\title{
Levels and avidities of antiphosphatidylethanolamine antibodies in patients with thrombotic events and immunologically-mediated diseases
}

\author{
Oliver Kuchara, , Milada Petrackova ${ }^{\mathrm{a}}$, Marta Kalousovaa ${ }^{\mathrm{a}}$, Libuse Noskova ${ }^{\mathrm{a}}$, Tomas Zima ${ }^{\mathrm{a}}$, Lenka Fialova ${ }^{\mathrm{a}, \mathrm{c}}$
}

\begin{abstract}
Aims. Antiphosphatidylethanolamine antibodies (aPE) represent one type of antiphospholipid antibody (aPL) directed against the neutral phospholipids - phosphatidylethanolamines. The aim of this study was to evaluate levels and avidities of aPE in several groups of patients and compare them with conventional aPLs.

Methods. aPE were analysed in a cohort consisting of 68 hospitalized patients. The other cohort comprised 22 patients with immunologically-mediated diseases. The control group consisted of 20 healthy persons. ELISA methods were used for determination of aPL. Avidities of aPE were tested by modified ELISA with urea as a chaotropic agent.

Results. aPE IgG/lgM were significantly higher in the group of patients with venous thromboembolism than those with non-thrombotic internal disorders ( $P=0.02$ for both Ig classes). aPE IgG/lgM elevated above cut-off values were found in $10.8 \%$ of patients with venous thromboembolism and as a single aPL in $6.5 \%$. Levels of aPE IgG higher than our limit $(>6 \mathrm{U} / \mathrm{mL}$ ) were detected in $29 \%$ of patients with immunologically-mediated diseases with other positive aPL. Low-, intermediate- and high-avidity aPE IgG were found in patients of both cohorts. The avidities of aPE IgG differed from those of anticardiolipin antibodies IgG. Neither APE IgG levels nor avidity dynamics significantly changed during follow-up.

Conclusion. aPE may be related to venous thromboembolism and may be part of the repertoire of aPL in immunologically-mediated diseases. There are patients with thrombosis negative for conventional aPL but positive for aPE. aPE IgG may have different avidities.
\end{abstract}

Key words: anticardiolipin antibodies, antiphosphatidylethanolamine antibodies, avidity, ELISA, chaotropic agents, urea, thrombosis, systemic lupus erythematosus

Received: October 14, 2021; Revised: January 24, 2022; Accepted: January 25, 2022; Available online: February 11, 2022 https://doi.org/10.5507/bp.2022.003

(c) 2022 The Authors; https://creativecommons.org/licenses/by/4.0/

anstitute of Medical Biochemistry and Laboratory Diagnostics, First Faculty of Medicine, Charles University and General University Hospital in Prague, Czech Republic

${ }^{b}$ Thomayer University Hospital, Czech Republic

'Department of Health Care and Population Protection, Faculty of Biomedical Engineering, Czech Technical University in Prague, Czech Republic

Corresponding author: Lenka Fialova, e-mail: Ifial@If1.cuni.cz

\section{INTRODUCTION}

Antiphospholipid antibodies (aPL) include a heterogeneous group of antibodies directed especially against negatively charged phospholipids alone and/or their complexes with various plasma proteins ${ }^{1,2}$. aPL contribute to various types of thrombotic and obstetric complications such as pregnancy loss, pre-eclampsia or placental insufficiency and are placed in context with valvular disease and some hematological disorders ${ }^{1}$. The mechanism of induction of these pathological conditions by aPL is complicated and involves the participation of various cells such as endothelial cells, monocytes, platelets, and proteins, e.g. complement ${ }^{1}$.

The persistently elevated levels of aPLs are laboratory criteria for the antiphospholipid syndrome (APS), which clinically manifests in thrombotic events and/or obstetric morbidity ${ }^{3,4}$.

Lupus anticoagulant, anticardiolipin antibodies $(\mathrm{aCL})$ and anti- $\beta 2$-glycoprotein I antibodies (aß2GPI) IgG and $\mathrm{IgM}$ are listed in the current laboratory criteria for APS diagnosis ${ }^{5}$. Testing is recommended for all of these antibodies, as patients with triple aPL-positivity are at a higher risk of thrombosis or pregnancy complications than double or single-positive cases ${ }^{5,6}$.

In addition to "classical" aPL, antibodies against other phospholipids or their complexes with proteins are also produced ${ }^{5}$. Testing of other aPLs has not been suggested yet ${ }^{5}$. However, patients with clinical symptoms of APS but without an increase in any of recommended aPLs were identified. This group of patients was classified as seronegative APS (SN-APS) (ref. ${ }^{7}$ ). aPL to other negatively charged phospholipids such as phosphatidylserine, phosphatidic acid or phosphatidylinositol known as non-criteria aPL have been detected in patients with SN-APS (ref. ${ }^{8}$ ). Antibodies directed against the phosphatidylserine-prothrombin complex (aPS/PT) have been studied in more detail. Recent studies suggest that the addition of aPS/PT to the recommended aPL could improve the estimation of thrombotic risk ${ }^{9,10}$. Non-criteria aPL tested in patients with APS also include those reacting with phosphatidylethanolamine (aPE) (ref. $\left.{ }^{11}\right)$. 
Phosphatidylethanolamines (PE) are the second most abundant mammalian membrane phospholipids, which constitute $20-50 \%$ of all phospholipids in mammalian cell membranes ${ }^{12}$. PE detected at the luminal endothelial surface may be susceptible to aPE binding, which is consistent with an association between the presence of aPE and idiopathic thrombosis ${ }^{13}$. Although aPEs have been studied in a number of clinical trials in patients with thrombosis, and pregnancy morbidities and other diseases, their diagnostic benefit remains controversial ${ }^{11,14-16}$. However, the pathogenicity of autoantibodies depends on various factors. One of them is their avidity. It is presumed that autoantibody avidity contributes to various clinical manifestations. There are studies on the avidity of common aPL, but to the best of our knowledge, the avidity of aPE has not been investigated yet ${ }^{17}$.

The aim of this study was to examine aPE in patients with thromboembolism, non-thrombotic internal and immunologically-mediated diseases. At the same time, we established the cut-off values for aPE IgG and IgM. We were interested not only in the levels of aPE, but also in their avidity. Therefore, another goal of the study was to introduce an ELISA method for determination of aPE IgG avidity using chaotropic agents and to evaluate aPE IgG avidity in selected groups of patients. We also monitored the dynamics of changes in the levels and avidities of aPE IgG. The last aim was to determine the relationship between aPE and conventional aPL.

\section{MATERIALS AND METHODS}

\section{Patients}

We analysed samples from two cohorts of patients one consisted of 68 patients hospitalized in Thomayer Hospital in Prague (TH cohort; age: $58 \pm 18$ years, mean \pm SD; sex: 32 females, 36 males) and the other cohort of patients examined at the Immunological Department of the Institute of Medical Biochemistry and Laboratory Diagnostics in Prague (ID cohort; $\mathrm{n}=22 ; 38 \pm 15$ years, mean \pm SD; sex: 17 females, 5 males).

In the $\mathrm{TH}$ cohort, patients were recruited randomly over a period of 3 years. We divided patients in the $\mathrm{TH}$ cohort into two groups. The first consisted of patients who were hospitalised for venous thromboembolism ( $n=46 ; 59 \pm 19$ years; sex: 22 females, 24 males). Patients with venous thrombosis in the lower limbs predominated $(n=42)$ and in addition, bilateral pulmonary embolism was concurrently diagnosed in 10 patients. Four patients were hospitalized for ischemic stroke. The diagnoses were performed by experienced internists based on valid diagnostic criteria using case history, clinical examination and Doppler-sonography in particular. The second group of non-thrombotic patients with various internal diseases included mainly those hospitalised with gastrointestinal or cardiometabolic disorders $(n=22 ; 56 \pm 16$ years; sex: 10 females, 12 males).

The ID cohort of patients with immunologically-mediated diseases comprised aCL IgG positive patients with systemic immunological diseases predominantly with systemic lupus erythematosus (SLE) or systemic connective tissue disease and infertility or kidney disorders.

We determined the levels of aCL, aPE, and the avidities of aPE in serum samples of patients. We also tested aPS/PT levels in patients of the TH cohort. In some patients not all parameters due to the lack of serum could be determined.

In addition to these two cohorts of patients, we examined a control group of 20 healthy subjects with the aim of establishing the limit values for aPE $\operatorname{IgG} / \operatorname{IgM}$ and aPS/PT Ig G/ IgM levels (age: $50 \pm 7$ years, mean \pm SD; sex: 10 females, 10 males).

All subjects gave written informed consent regarding participation in the study. The Ethics Committees of the General University Hospital, Prague and Thomayer Hospital, Prague, approved the study.

\section{Methods}

Levels of various types of antiphospholipid antibodies aPE $\operatorname{IgG} / \operatorname{IgM}$ and aPS/PT IgG/IgM were analysed by ELISA kits (AESKULISA Ethanolamin-GM and AESKULISA Serine-Prothrombin-GM, AESKU. DIAGNOSTICS, Wendelsheim, Germany). aCL IgG/ IgM and a 32 GPI IgG levels were determined by the ELISA kits (ELISA Anti-cardiolipin antibodies, Orgentec, Mainz, Germany). Used ELISA kits have CE IVD (In Vitro Diagnostic Medical Devices) certifications. ELISA assays were performed according to the manufacturer's instructions. Serum samples were diluted 1:101 and 1:100 for $\mathrm{aPE}$ IgG/IgM or aPS/PT IgG/IgM and aCL or a $\beta 2 \mathrm{GPI}$ analyses, respectively.

Phosphatidylethanolamine or cardiolipin plus native human 32-glycoprotein I and native phosphatidylserine plus human native prothrombin were used for coating on microwells in aPE or aCL ELISAs and aPS/PT ELISA, respectively. The ELISA kits for aCL IgG/IgM and a $\beta 2$ GPI IgG (Orgentec) are calibrated against the internationally recognised reference sera from E.N. Harris, Louisville and the specific reference material IRP 97/656 (IgG) and HCAL (IgG) / EY2C9 (IgM). The results were expressed in units GPL (aCL IgG) and MPL (aCL IgM) or arbitrary units $\mathrm{U} / \mathrm{mL}$ (aß2GPI IgG). The standards in the ELISA kits for aPE IgG/IgM and aPS/PT IgG/IgM (AESKU. DIAGNOSTICS) contained human serum. The levels of aPE $\mathrm{IgG} / \mathrm{IgM}$ and aPS/PT IgG/IgM were expressed in $\mathrm{U} / \mathrm{mL}$.

\section{Avidity of aPE IgG}

aPE IgG avidity was determined by the modified ELISA method using chaotropic agents described in details in previous studies ${ }^{18,19}$. The wells of microtiter strips were coated with $50 \mu \mathrm{L}$ of phosphatidylethanolamine 50 $\mu \mathrm{g} / \mathrm{mL}$ (Merck KGaA, Darmstadt, Germany). We utilized urea as a chaotropic agent, similarly as in our avidity assay for aCL IgG. Initially, we tested different urea concentrations $-2 \mathrm{~mol} / \mathrm{L}, 4 \mathrm{~mol} / \mathrm{L}, 6 \mathrm{~mol} / \mathrm{L}$ and $8 \mathrm{~mol} / \mathrm{L}$ in sera diluted $1: 50,1: 100$ and $1: 200$ to find the optimal conditions for aPE IgG avidity determination. 
The results of aPE IgG avidity were expressed as the ratio of the antibodies bound in the wells with chaotrope to the total antibodies bound in the absence of a chaotrope.

$$
\mathrm{AI}=\frac{\text { absorbance in the wells with chaotrope }}{\text { absorbance in the wells without chaotrope }}
$$

We classified the antibodies with AI $>0.6$ as high-avidity, while those characterised by $\mathrm{AI}<0.4$ were low-avidity. The range of AI from 0.4 to 0.6 indicated intermediateavidity $^{20,21}$.

\section{Statistical analysis}

The Shapiro-Wilk test was used to test the normality of the data. Since this was not normal, nonparametric tests were used. The comparison of two groups we used the Mann-Whitney test. The Spearman correlation coefficient or Passing-Bablok regression was applied to analyse the relationship of variables. The paired measurements were evaluated by the Wilcoxon matched pairs test. Fischer's exact test was performed for comparison of the qualitative data. The level of statistical significance was set to 0.05. Statistical analyses were performed in the Medcalc (MedCalc, Ostend, Belgium).

To express reference limits for aPE $\operatorname{IgG} / \operatorname{IgM}$ and PS $\mathrm{IgG} / \mathrm{IgM}$, we applied the robust method according to the document of Clinical and Laboratory Standards Institute (CLSI) C28-A3 recommended for the evaluation of smaller number of reference subjects ${ }^{22}$ using MedCalc software.

\section{RESULTS}

\section{Cut-off values (upper limits) for aPE IgG/IgM and aPS/PT IgG/IgM}

We established the cut-off values for aPE IgG/ IgM and aPS/PT IgG/IgM in 20 healthy persons using $95 \%$ reference intervals. The clinically important cut-off values (upper limits) are shown in Table 1. We used these values in further evaluation of aPL in our patients.

The values recommended by the manufacturer of the ELISA kit were utilized in aCL (>10 GPL for aCL IgG, $>7 \mathrm{MPL}$ for aCL $\operatorname{IgM})$ and a $32 \mathrm{GPI} \operatorname{IgG}(>8 \mathrm{U} / \mathrm{mL})$.

Table 1. Cut-off values (upper limits) for aPE $\operatorname{IgG} / \operatorname{IgM}$ and aPS/PT IgG/IgM in 20 healthy persons.

\begin{tabular}{lc}
\hline Type of aPL & Upper limit $(\mathrm{U} / \mathrm{mL})$ \\
\hline aPE IgG & 6 \\
aPE IgM & 13.2 \\
aPS/PT IgG & 6.7 \\
aPS/PT IgM & 5.3 \\
\hline
\end{tabular}

aPE - antiphosphatidylethanolamine antibodies, aPS/PT - antibodies against the phosphatidylserine-prothrombin complex, IgG - immunoglobulin G, IgM - immunoglobulin M

\section{Levels of tested aPL in patients with thromboembolism}

The comparison of non-criteria aPL antibodies showed significant differences for aPE IgG and IgM between groups of patients with venous thromboembolism and those with non-thrombotic internal diseases (Fig. 1A-F). These antibodies were significantly higher in patients with venous thromboembolism ( $\mathrm{aPE} \operatorname{IgG}$ and $\operatorname{IgM}, P=0.02$ for both Ig classes). However, no significant differences between these patients' groups and the control group were observed with the exception of significantly higher aPE IgM in controls than in non-thrombotic internal disease $(P=0.04)$. Levels of aPS/PT IgG or IgM were similar in both groups of patients. No significant differences were found for aCL IgG or IgM levels and a 32 GPI IgG.

Fig. 2A shows the levels of aPL tested in patients with pulmonary embolism. aPL levels above the upper limits of our normative values were found only in two patients with pulmonary embolism (one patient had increased aPE IgM, the other patient had increased other aPLs). Once, aCL IgG and aPS/PT IgG values were higher than the corresponding cut-off limits in patients with ischemic stroke (Fig. 2B).

Patients with thromboembolism and increased aPLs upper cut-off limits are listed in Table 2. 32.6\% of patients with thromboembolic diseases had at least one of the tested aPL antibodies increased. aCL IgG/IgM were elevated in $19.5 \%$, and similarly also aPS/PT IgG/IgM, followed by increased aPE $\mathrm{IgG} / \mathrm{IgM}$ in $10.8 \%$ of patients. An isolated increase in aCL $\mathrm{IgG} / \mathrm{IgM}$ as well as aPE $\mathrm{IgG} / \mathrm{IgM}$ was observed in $6.5 \%$ of patients for each of the antibodies. aPS/PT IgG/IgM were elevated as a single aPL in the $8.6 \%$ of patients (Table 3 ). a 32 GPIs were not increased in any patient with thromboembolic diseases. In the patients with non-thrombotic internal diseases, only one patient had an increased aPL, namely aCL IgM. No significant differences were found in aPE $\operatorname{IgG} / \operatorname{IgM}$ and $\mathrm{aPS} / \mathrm{PT} \mathrm{IgG} /$ $\operatorname{IgM}$ positive patients with thromboembolism and control.

\section{Levels of tested aPL in patients with immunologically-mediated disorders}

Patients selected to the ID cohort had elevated aPL IgG levels determined by ELISA antiphospholipid screen including aCL, aPS, phoshatidylinositol (aPI) and phosphatidic acid antibodies (aPA), but not aPE. All patients of ID cohort were also positive for aCL IgG (>10 GPL). Only aPE IgG was examined in 17 patients from the ID cohort of patients. Some patients were examined repeatedly, so that we examined aPE IgG in 26 samples in total. The levels of aPE IgG were significantly higher than in controls $(P<0.001)$. The levels of aPE IgG higher than our cut-off value $(>6 \mathrm{U} / \mathrm{mL})$ were detected at least once in five patients (29\%). Three of these patients were followed for SLE or for systemic connective tissue disease, one patient for interstitial nephritis and one woman was treated for infertility. Table 4 summarizes the results of the aPL IgG tests against various phospholipids / proteins performed as part of an immunological examination in five patients with elevated aPE IgG. All patients were also positive for other aPL IgG against other phospholipids / proteins. No significant differences between the $1^{\text {st }}$ and 
Table 2. Patients with thromboembolism and positive aPL.

\begin{tabular}{|c|c|c|c|c|c|c|c|c|c|c|}
\hline $\begin{array}{l}\text { Patient } \\
\text { No. }\end{array}$ & $\begin{array}{l}\mathrm{aCL} \text { IgG } \\
\text { (GPL) }\end{array}$ & $\begin{array}{l}\text { aCL IgM } \\
\text { (MPL) }\end{array}$ & $\begin{array}{l}\mathrm{a} \beta 2 \mathrm{GPI} \\
\mathrm{IgG} \\
(\mathrm{U} / \mathrm{mL})\end{array}$ & $\begin{array}{l}\text { aPE IgG } \\
(\mathrm{U} / \mathrm{mL})\end{array}$ & $\begin{array}{l}\text { aPE IgM } \\
(\mathrm{U} / \mathrm{mL})\end{array}$ & $\begin{array}{l}\mathrm{aPS} / \mathrm{PT} \\
\mathrm{IgG} \\
\mathrm{U} / \mathrm{mL})\end{array}$ & $\begin{array}{l}\text { aPS/PT IgM } \\
(\mathrm{U} / \mathrm{mL})\end{array}$ & Sex & $\begin{array}{l}\text { Age } \\
\text { (year) }\end{array}$ & Type of venous thromboembolism \\
\hline 1 & 4.64 & 1.74 & 4.40 & 1.54 & 16.15 & 3.08 & 0.24 & $f$ & 50 & $\begin{array}{l}\text { Ilio-femoro-popliteo-crural } \\
\text { phlebothrombosis of left lower limb }\end{array}$ \\
\hline 2 & 2.98 & 0.60 & 4.20 & 0.69 & 1.34 & 9.76 & 0 & $\mathrm{~m}$ & 85 & $\begin{array}{l}\text { Femoro-popliteal phlebothrombosis } \\
\text { of right lower limb }\end{array}$ \\
\hline 3 & 4.31 & 7.00 & 2.80 & 2.99 & 26.01 & 2.41 & 4.41 & $\mathrm{~m}$ & 69 & $\begin{array}{l}\text { Femoro-popliteo-crural } \\
\text { phlebothrombosis of left lower limb }\end{array}$ \\
\hline 4 & 5.08 & 9.41 & 3.00 & 0.96 & 3.14 & 4.38 & 9.02 & $\mathrm{~m}$ & 47 & $\begin{array}{l}\text { Ilio-femoro-popliteo-crural } \\
\text { phlebothrombosis of right lower limb }\end{array}$ \\
\hline 5 & 4.38 & 3.54 & 3.40 & 1.76 & 7.45 & 3.00 & 6.31 & $\mathrm{~m}$ & 57 & $\begin{array}{l}\text { Femoro-popliteal phlebothrombosis } \\
\text { of left lower limb }\end{array}$ \\
\hline 6 & 3.13 & 2.55 & 2.00 & 7.55 & 3.77 & 1.18 & 1.31 & $f$ & 71 & $\begin{array}{l}\text { Femoro-popliteo-crural } \\
\text { phlebothrombosis of left lower limb }\end{array}$ \\
\hline 7 & 11.16 & 13.50 & 2.06 & 1.11 & 9.32 & 10.48 & 6.92 & $\mathrm{f}$ & 84 & $\begin{array}{l}\text { Femoro-popliteo-crural } \\
\text { phlebothrombosis of left lower limb } \\
\text { Pulmonary embolism }\end{array}$ \\
\hline 8 & 2.38 & 1.60 & 1.30 & 3.85 & 22.34 & 0.85 & 1.30 & $f$ & 42 & $\begin{array}{l}\text { Femoro-popliteo-crural } \\
\text { phlebothrombosis of left lower limb } \\
\text { Pulmonary embolism }\end{array}$ \\
\hline 9 & 4.92 & 14.59 & 1.90 & 1.18 & 2.85 & 3.58 & 13.48 & $\mathrm{~m}$ & 73 & $\begin{array}{l}\text { Ilio-femoro-popliteal } \\
\text { phlebothrombosis of right lower limb }\end{array}$ \\
\hline 10 & 3.07 & 7.73 & 3.10 & 1.77 & 3.91 & 3.30 & 4.59 & $\mathrm{f}$ & 75 & $\begin{array}{l}\text { Ilio-femoro-popliteal } \\
\text { phlebothrombosis of right lower limb }\end{array}$ \\
\hline 11 & 11.50 & 3.37 & 2.10 & 1.29 & 2.67 & 3.77 & 1.24 & $\mathrm{~m}$ & 67 & Ischemic stroke \\
\hline 12 & 9.88 & 3.08 & 2.50 & 1.58 & 1.04 & 32.41 & 0.56 & $\mathrm{~m}$ & 73 & Ischemic stroke \\
\hline 13 & 46.87 & 1.77 & 3.70 & 11.89 & 0.36 & 46.28 & 0 & f & 64 & $\begin{array}{l}\text { Crural phlebothrombosis of right } \\
\text { lower limb }\end{array}$ \\
\hline 14 & 6.71 & 10.10 & 2.50 & 3.01 & 11.05 & 6.61 & 2.11 & $\mathrm{f}$ & 62 & $\begin{array}{l}\text { Ilio-femoro-popliteo-crural } \\
\text { phlebothrombosis of right lower limb }\end{array}$ \\
\hline 15 & 2.8 & 2.6 & 2.6 & 0.76 & 6.76 & 2.54 & 6.02 & $\mathrm{~m}$ & 49 & $\begin{array}{l}\text { Popliteo-crural } \\
\text { phlebothrombosis of left lower limb }\end{array}$ \\
\hline
\end{tabular}

Increased aPL are indicated in bold. The cut-off limits for non-criteria aPL are given in Table 1 and cut-off limit for aCL >10 GPL for aCL IgG, $>7$ MPL for aCL IgM.

a 32 GPI - antibodies against $\beta 2$-glycoprotein I, aCL - anticardiolipin antibodies, aPL - antiphospholipid antibodies, aPE - antiphosphatidylethanolamine antibodies, aPS/PT - antibodies directed against the phosphatidylserine-prothrombin complex, IgG - immunoglobulin G, IgM - immunoglobulin M, GPL - IgG phospholipid units, MPL - IgM phospholipid units, f - female, m - male

$2^{\text {nd }}$ measurement of APE IgG levels were found in repeatedly examined patients $(n=8)$. Two patients experienced a change with an overlap to above limit level.

\section{Avidity of aPE IgG}

Initial experiments to establish the optimal conditions for the determination of aPE IgG avidity involved analyses of variously diluted sera at different urea concentrations (Fig. 3). Higher urea concentrations dissociated interactions in immune complexes formed between aPE IgG and PE bound on the surface of the microtiter well more effectively than lower ones. Higher serum dilutions (1:100, $1: 200)$ resulted in some samples in too low absorbances and thus to lower accuracy of results. Urea of $6 \mathrm{~mol} / \mathrm{L}$ or $8 \mathrm{~mol} / \mathrm{L}$ at a 1:50 dilution of sera appeared to be suitable, because these conditions allowed us to sufficiently disrupt immune complexes ${ }^{23}$. Comparison of AI using urea $6 \mathrm{~mol} / \mathrm{L}$ and $8 \mathrm{~mol} / \mathrm{L}$ showed a significant correla- tion ( $\mathrm{n}=48, \mathrm{r}=0.71, P<0.0001)$ determined Passing-Bablok regression.

We examined the aPE IgG avidity using urea $6 \mathrm{~mol} / \mathrm{L}$ at 1:50 dilution in 43 patients with thromboembolism in the TH cohort and in 38 sera in the ID cohort (22 patients). Patients with venous thromboembolism synthesised low-, intermediate and high-avidity aPE IgG, AI values ranging from $0.23-0.87$. The low-avidity aPE IgG (AI less than 0.4 ) was observed in $25 \%$, intermediateavidity aPE IgG (AI 0.4-0.6) in 35\% and those with highavidity (AI more than 0.6 ) in $40 \%$ of patients (Fig. 4A). AI values in immunological patients varied from 0.13 to 0.78 . Low-avidity aPE IgG was similar as those in the immunological patients ( $27 \%$ ), intermediate avidity in $46 \%$ and high-avidity again in $27 \%$ of patients (Fig. 4B). In repeatedly examined patients, we evaluated avidity only in the first sample. The aPE IgG avidity in patients examined a second time did not differ significantly from the previous examination. 

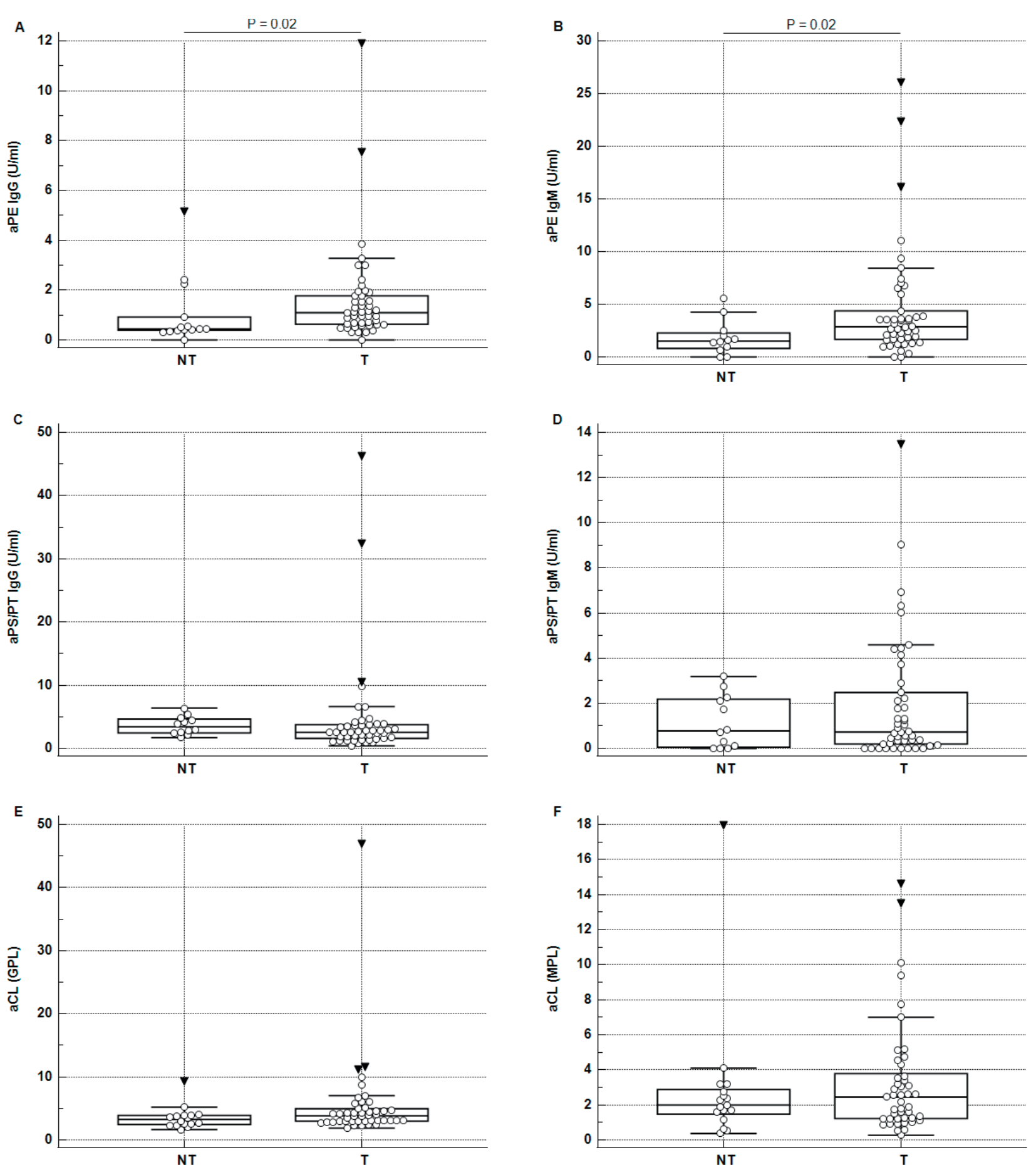

Fig. 1. Serum levels of aCL and non-criteria aPL in patient groups with thromboembolisms (T group) and non-thrombotic internal diseases (NT group).

(A) aPE IgG levels, (B) aPE IgM levels, (C) aPS/PT IgG levels, (D) aPS/PT IgM levels, (E) aCL IgG levels and (F) aCL IgM levels

Levels of aPE $\mathrm{Ig} / \mathrm{IgM}$ in patients with thrombosis were significantly higher than those with non-thrombotic internal disorders $(P=0.02)$. Other tested aPL did not significantly differ between patient groups.

The central box defines the values from the $25^{\text {th }}$ to $75^{\text {th }}$ percentiles. A horizontal line is drawn at the median. The vertical line shows the minimum to the maximum value, excluding outside and far out values. Far out values are indicated by a black triangle.

aCL - anticardiolipin antibodies, aPL - antiphospholipid antibodies, aPE - antiphosphatidylethanolamine antibodies, aPS/PT - antibodies directed against the phosphatidylserine-prothrombin complex, IgG - immunoglobulin G, IgM - immunoglobulin M, GPL - IgG phospholipid units, MPL - IgM phospholipid units 

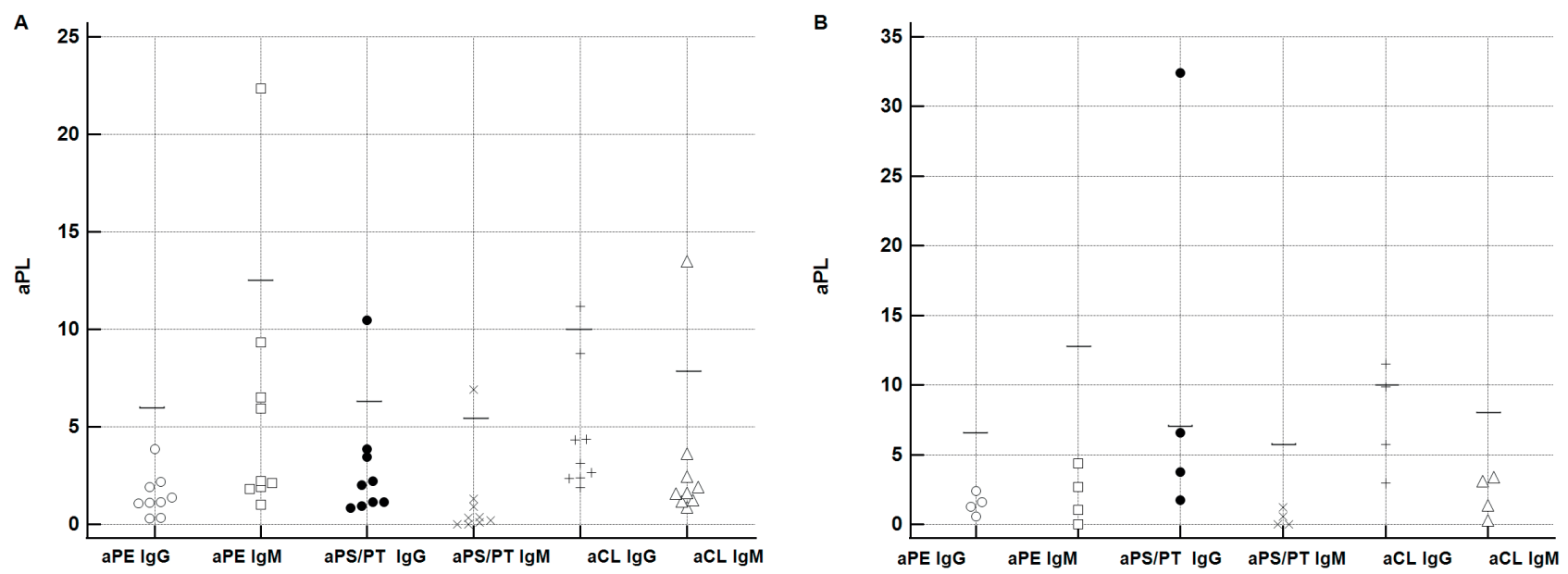

Fig. 2. Serum levels of aCL and non-criteria aPL in patient groups.

(A) pulmonary embolism and (B) ischemic stroke

The levels of aCL IgG/IgM are expressed in phospholipid units GPL/MPL, aPE IgG/IgM and aPS/PT IgG/IgM in U/mL. The cut-off values are shown by a horizontal line at each of the aPLs.

With the exception of aPE IgG, only one value for each of the aPLs exceeded the cut-off for the respective antibody in patients with pulmonary embolism. Only one aCL IgG as well as one aPS/PT IgG value were higher than the corresponding cut-off limits in patients with ischemic stroke.

aCL - anticardiolipin antibodies, aPL - antiphospholipid antibodies, aPE - antiphosphatidylethanolamine antibodies, aPS/PT - antibodies directed against the phosphatidylserine-prothrombin complex, IgG - immunoglobulin G, IgM - immunoglobulin M

AI values for aCL IgG avidity determined by a similar procedure to a previous study ${ }^{24}$ were significantly higher than those for aPE IgG in the group of patients with thromboembolism $(P<0.0001)$ as well as with immunologically-mediated diseases $(P=0.04)$. APE IgG avidities in immunological patients did not correlate with those of aCL IgG, while in those with thromboembolism the avidities of aPE and aCL correlated $(\mathrm{r}=0.36, P=0.02)$.

\section{Relationship between aPE and other aPL}

TH cohort - aPE IgG levels significantly correlated with aCL IgG only in a group of patients with thromboembolism $(\mathrm{r}=0.31, P=0.04)$. Another significant correlation was demonstrated between aPE IgM and aCL IgM $(\mathrm{r}=0.54, P=0.0001)$ or aPS/PT $\operatorname{IgM}(\mathrm{r}=0.58, P<0.0001)$ in the same patient group. In addition, aPE IgM significantly correlated with aPS/PT IgM $(\mathrm{r}=0.79, P=0.002)$ also in the group of patients with non-thrombotic internal diseases and controls.

Concerning the ID cohort, there was no significant correlation between aPE IgG and aCL IgG or other noncriteria aPLs (aPS, aPI, and aPA) examined during followup in the group of patients with immunologically-mediated diseases. A significant correlation was also found between aPE IgM and aPS/PT IgM ( $\mathrm{r}=0.51, P=0.02)$ in controls.

\section{DISCUSSION}

The aim of the study was to examine $\mathrm{aPE}$ IgG and/or IgM in patients with thromboembolism, non-thrombotic internal and immunologically-mediated diseases. The evaluation of aPE was not limited to levels, it included their avidities. The dynamics of aPE IgG levels and avidities were monitored in a subset of patients. Our study demonstrated significantly higher levels of aPE IgG and IgM

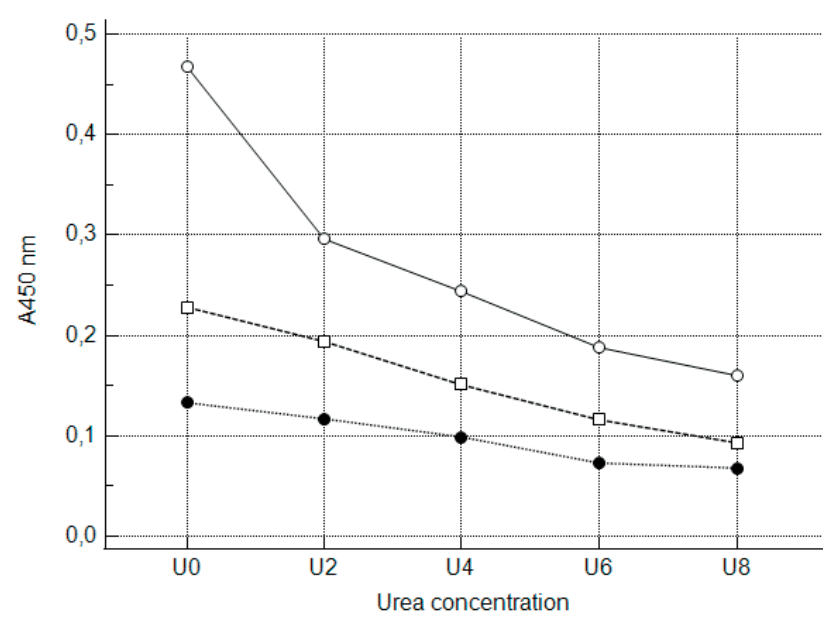

Fig. 3. aPE binding at several urea concentrations in sera diluted 1:50, 1:100 and 1:200.

Urea concentration - U0 without urea, U2 - $2 \mathrm{~mol} / \mathrm{L}, \mathrm{U} 4$ - $4 \mathrm{~mol} / \mathrm{L}$, $\mathrm{U} 6$ - $6 \mathrm{~mol} / \mathrm{L}$, U8 - $8 \mathrm{~mol} / \mathrm{L}$

Serum dilution: solid line $-1: 50$, dashed line 1:100, dotted line 1:200

in a cohort of patients with venous thromboembolisms compared to those with other internal diseases and in the cohort of immunologically-mediated diseases than in controls. Increases in aPE IgG and / or IgM levels above our cut-off values (95th percentile of the control group) were observed only in $10.8 \%$ of patients with thrombosis while in patients with immunologically-mediated diseases in $29 \%$. APE IgG levels appear to be stable. It seems that aPE IgG/IgM may be related to other aPLs, but only in some patient groups. The avidities of aPE IgG can range from low-avidity to high-avidity antibodies in various diseases. As in the case of aPE IgG levels, their avidities did not show significant dynamics upon repeated examination. 
Table 3. Proportion of increased aPL in patients with thromboembolism $(n=46)$.

\begin{tabular}{|c|c|c|c|c|c|c|}
\hline & aCL IgG & aCL IgM & aPE IgG & aPE IgM & aPS/PT IgG & aPS/PT IgM \\
\hline Increased aPL (number /\%) & $3(6.5 \%)$ & $6(13 \%)$ & $2(4.3 \%)$ & $3(6.5 \%)$ & $4(8.7 \%)$ & $5(10.8 \%)$ \\
\hline Isolated increased aPL (number $/ \%$ ) & $1(2.2 \%)$ & $2(4.3 \%)$ & $1(2.2 \%)$ & $2(4.3 \%)$ & $2(4.3 \%)$ & $2(4.3 \%)$ \\
\hline
\end{tabular}

aCL - anticardiolipin antibodies, aPL - antiphospholipid antibodies, aPE - antiphosphatidylethanolamine antibodies, aPS/PT - antibodies directed against the phosphatidylserine-prothrombin complex, IgG - immunoglobulin G, IgM - immunoglobulin M

Table 4. Patients with immunologically-mediated diseases and increased aPE IgG.

\begin{tabular}{ccccccccccc}
\hline $\begin{array}{l}\text { No of } \\
\text { patients }\end{array}$ & aPE IgG & aCL IgG & $\begin{array}{c}\text { aPL IgG } \\
\text { screen }\end{array}$ & $\begin{array}{c}\text { aß2GPI } \\
\text { IgG }\end{array}$ & aPS IgG & aPI IgG & aPA IgG & Sex & $\begin{array}{l}\text { Age } \\
\text { (year) }\end{array}$ & Diagnosis \\
\hline 1 & 9.13 & 31.3 & 42.2 & 44.6 & 22.7 & 30.3 & 28.8 & $\mathrm{f}$ & 33 & Infertility \\
2 & 25.27 & 80.9 & $>100$ & 44.4 & 57.5 & 38.9 & 87.1 & $\mathrm{~m}$ & 46 & SLE \\
3 & 14.95 & $>100$ & 98.5 & 71.8 & 90.9 & 78.9 & 99.6 & $\mathrm{f}$ & 32 & $\begin{array}{l}\text { Systemic connective } \\
\text { tissue disease } \\
\text { Tubulo-interstitial } \\
\text { nephritis }\end{array}$ \\
& 7.31 & 49.0 & 34.2 & 33.8 & 39.4 & 33.3 & 43.7 & $\mathrm{f}$ & 12 & SLE \\
\hline
\end{tabular}

Levels of aCL IgG and other aPL are expressed in GPL and U/mL, respectively.

aß2GPI - antibodies against $\beta 2$-glycoprotein I, aCL - anticardiolipin antibodies, aPA - antiphosphatidic acid antibodies, aPE - antiphosphatidylethanolamine antibodies, aPI - antiphosphatidylinositol antibodies aPS - antiphosphatidylserine antibodies, IgG - immunoglobulin G, GPL - IgG phospholipid units, SLE - systemic lupus erythematosus

Several studies have already described the relationship between the main clinical manifestations of APS and the presence of antibodies to the neutral phospholipid phosphatidylethanolamine ${ }^{11}$. The positivity of aPE in our patients with thromboembolism was similar to that in the multicentre study of Sanmarco et al. ${ }^{25}$. The proportion of elevated aPE IgG/IgM levels was the lowest among the examined aPLs, but it was the only positive aPL in $6.5 \%$ of patients. Therefore, we supported the opinion that aPE may be the only type of aPL in patients with thrombosis ${ }^{26}$.

As expected, the proportion of positive aPE IgG was higher, more than two-fold (29\%) in patients with immunologically-mediated diseases compared to patients with thrombosis. However, it should be taken into account that the cohort of patients with immunologically-mediated diseases included patients who were aCL IgG positive. The result is close to that of a study by Bertolaccini et al. ${ }^{27}$, which showed aPE IgG in $46 \%$ of patients with SLE and at the same time aPL positive. In contrast, Zhang et al. ${ }^{28}$ reported aPE positivity in only $8.1 \%$ of Chinese patients with APS. Either commercial kits or in-house ELISA methods can be used to determine aPE. Unfortunately, there are no international standards for aPE as for conventional aPLs. In addition, the impact of variously modified ELISA methods on the results has been demonstrated ${ }^{29,30}$. This makes it difficult to compare different studies and may lead to ambiguous results.

The observation of stable aPE levels in patients followed over time was consistent with Sanmarco et al. ${ }^{25}$ but this focused on patients with thrombosis.

The association between aPE and other aPLs is unclear. Consistently with Bertolaccini et al. ${ }^{27}$ we also found no relationship between aPE IgG and aPL IgG against negatively charged phospholipids in patients with immu-

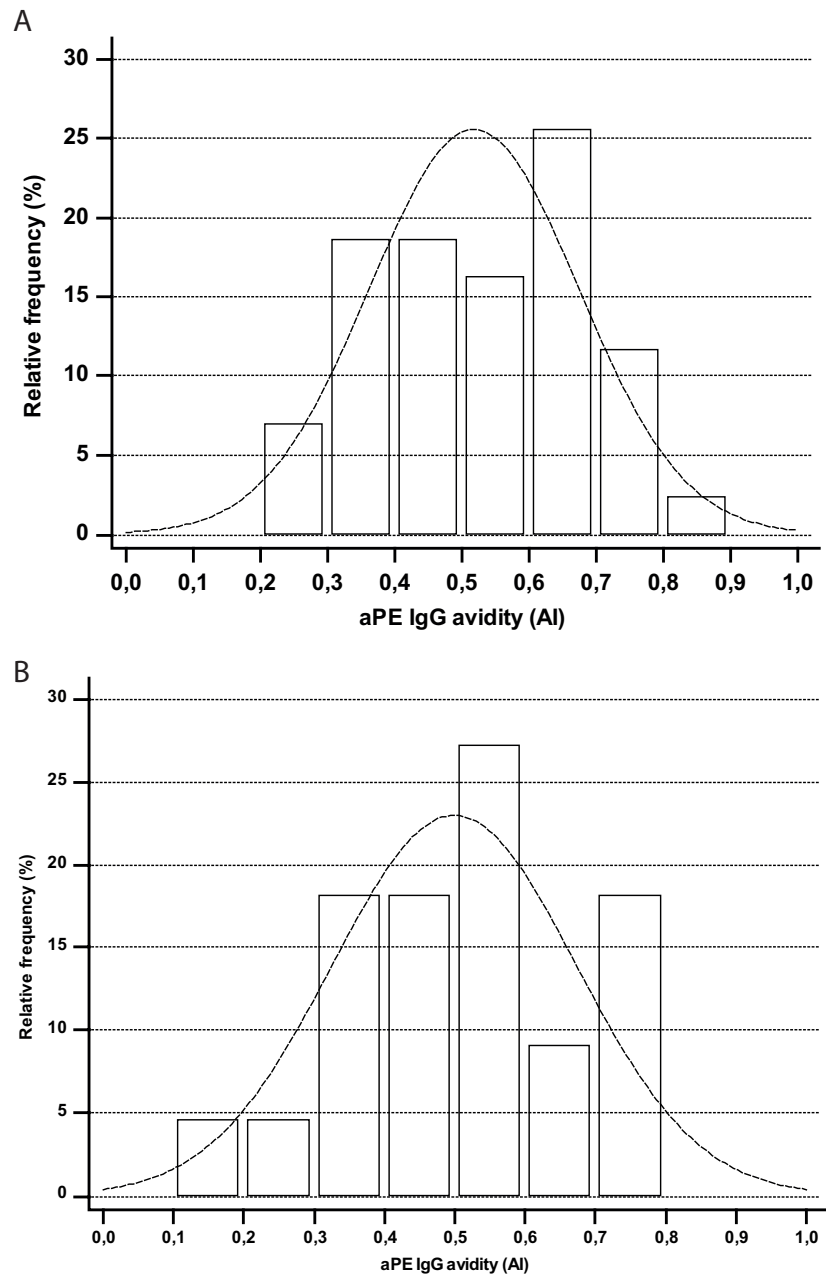

Fig. 4. Distribution of aPE IgG avidity.

(A) in patients with thromboembolism; (B) in patients with immunologically-mediated diseases $\mathrm{AI}$ - avidity index 
nologically-mediated diseases. However, aPE IgG/IgM levels correlated with aCL $\operatorname{IgG} / \operatorname{IgM}$ in the thromboembolism group which may indicate a common involvement of both aPL antibodies in this pathological manifestation.

Not only the levels of antibodies, but also their avidities have an impact on the severity of autoimmune disease ${ }^{17}$. To our knowledge, no previous studies have investigated this aspect of aPE. There are various methodological approaches for determining the avidity of autoantibodies. Commonly used assays are ELISA in the presence of various chaotropic agents which disrupt the bonds between the antigen coated on the surface of the well and the corresponding antibody. These ELISA methods have already been described for testing the avidity of aPL IgG, specifically aCL or a aß2GPI (ref. ${ }^{31,32}$ ). For this reason, we also chose a modified ELISA using urea as a chaotropic agent to test the avidity of aPE.

A pilot study of avidity determination showed that the avidity of aPE IgG can vary over a wide range. Interestingly, we did not demonstrate any relationship between the avidity of aPE IgG and aCL IgG in patients with immunologically-mediated diseases. While low- and medium- avidity antibodies were mainly represented among APEs, higher avidity antibodies predominated in aCL. A similar finding was made by Totland et al. ${ }^{33}$, who examined the avidity of common onconeural antibodies anti-Hu and anti-Yo and observed that anti-Yo generally had higher avidity than anti-Hu. It can be assumed that different aPLs may be involved in the pathogenesis of the disease in various ways, not only with respect to different binding targets. This is known from the studies on the avidity (affinity) of other autoantibodies ${ }^{17}$. For example, high-avidity IgG antinuclear antibodies could be a potential biomarker for the assessment of the prognosis of SLE activity $^{34}$. Conversely, in another study, the levels as well as the avidity of antibodies to amyloid $\beta$ were lower in patients with Alzheimer's disease than in healthy controls ${ }^{35}$.

The avidities of aPE IgG expressed as AI in most patients with immunologically-mediated diseases did not differ significantly during patient follow-up, i.e. there was no switching between low-avidity and high-avidity antibody categories. It can be assumed that the examination of avidity took place in the period when the value of avidity was already differentiated.

\section{CONCLUSION}

In conclusion, we confirmed that aPE may be related to venous thromboembolism and may be part of the repertoire of aPL in immunologically-mediated diseases. aPE IgG may have different avidities, but low and medium avidities predominate. The clinical relevance of avidity testing will need to be verified in a larger cohort of patients.

Acknowledgements: This work was supported by the project of Ministry of Health, Czech Republic for conceptual development of research organization
RVO-VFN64165/2012 (General University Hospital in Prague, Czech Republic), by the research project of Charles University in Prague PROGRES Q25 206025-5 and BBMRI-CZ LM2018125 and by Institutional support for the development of a research organization.

We wish to thank Dr. Karin Malíčková for the selection of the serum samples for our avidity analyses and for the providing of the antiphospholipid antibody values in patients carried out at the Immunological Department.

Author contributions: OK: study design, collection of samples, clinical data of patients with thrombosis, manuscript editing; MP: ELISA analyses; MK: critical reading and review of the manuscript; LN: data collection, manuscript editing; TZ: critical reading and review of the manuscript; LF: study design, data collection, statistical analysis, manuscript writing.

Conflict of interest statement: The authors state that there no conflicts of interest regarding the publication of this article.

\section{REFERENCES}

1. Ruiz-Irastorza G, Crowther M, Branch W, Khamashta MA. Antiphospholipid syndrome. Lancet 2010;376:1498-509.

2. Misasi R, Capozzi A, Longo A, Recalchi S, Lococo E, Alessandri C, Conti F, Valesini G, Sorice M. "New" antigenic targets and methodological approaches for refining laboratory diagnosis of antiphospholipid syndrome. J Immunol Res 2015;2015:858542.

3. Hughes GR. Thrombosis, abortion, cerebral disease, and the lupus anticoagulant. Br Med J (Clin Res Ed) 1983;287:1088-9.

4. Schreiber K, Sciascia S, de Groot PG, Devreese K, Jacobsen S, Ruiz-Irastorza G, Salmon JE, Shoenfeld Y, Shovman O, Hunt BJ. Antiphospholipid syndrome. Nat Rev Dis Primers 2018;4:17103.

5. Devreese KMJ, Ortel TL, Pengo V, de Laat B. Subcommittee on Lupus Anticoagulant/Antiphospholipid A. Laboratory criteria for antiphospholipid syndrome: communication from the SSC of the ISTH. J Thromb Haemost 2018;16:809-13.

6. Devreese KMJ. How to Interpret Antiphospholipid Laboratory Tests. Curr Rheumatol Rep 2020;22:38.

7. Hughes GR, Khamashta MA. Seronegative antiphospholipid syndrome. Ann Rheum Dis 2003;62:1127.

8. Bradacova P, Slavik L, Ulehlova J, Skoumalova A, Ullrychova J, Prochazkova J, Hlusi A, Manukyan G, Kriegova E. Current Promising Biomarkers and Methods in the Diagnostics of Antiphospholipid Syndrome: A Review. Biomedicines 2021;9:166.

9. Zigon P, Podovsovnik A, Ambrozic A, Tomsic M, Hocevar A, Gaspersic N, Rotar Z, Praprotnik S, Semrl SS, Cucnik S. Added value of noncriteria antiphospholipid antibodies for antiphospholipid syndrome: lessons learned from year-long routine measurements. Clin Rheumatol 2019;38:371-8.

10. Tonello M, Mattia E, Favaro M, Del Ross T, Calligaro A, Salvan E, Hoxha A, Fedrigo M, Ruffatti A. IgG phosphatidylserine/prothrombin antibodies as a risk factor of thrombosis in antiphospholipid antibody carriers. Thromb Res 2019;177:157-60.

11. Staub HL, Bertolaccini ML, Khamashta MA. Anti-phosphatidylethanolamine antibody, thromboembolic events and the antiphospholipid syndrome. Autoimmun Rev 2012;12:230-4.

12. Vance JE. Phosphatidylserine and phosphatidylethanolamine in mammalian cells: two metabolically related aminophospholipids. J Lipid Res 2008;49:1377-87.

13. Zhixin L, Wells CW, North PE, Kumar S, Duris CB, Mclntyre JA, Ming Z. Phosphatidylethanolamine at the luminal endothelial surface-implications for hemostasis and thrombotic autoimmunity. Clin Appl Thromb Hemost 2011;17:158-63.

14. Butkiewicz F, Kaszuba M, Brzezinski M, Izbicki J, Kubis M, Lopinski H, Borowiak M, Szelepajlo M, Fischer K, Flicinski J. Associations between the incidence of antiphosphatidylserine and antiphosphatidyletha- 
nolamine antibodies and clinical manifestations of systemic lupus erythematosus. Pol Arch Med Wewn 2014;124:573-8.

15. Dima A, Caraiola $S$, Jurcut $C$, Balanescu E, Balanescu $P$, Ramba D, Badea C, Pompilian V, lonescu R, Baicus A, Baicus C, Dan GA. Extended Antiphospholipid Antibodies Screening in Systemic Lupus Erythematosus Patients. Rom J Intern Med 2015;53:321-8.

16. Caraiola S, Jurcut C, Dima A, Baicus C, Baicus A. Antiphosphatidylethanolamine Antibodies and Deep Vein Thrombosis in Lupus Patients with Antiphospholipid Syndrome. Revista Romana De Medicina De Laborator 2018;26:243-50.

17. Fialova L. Avidity of antiphospholipid antibodies - our current knowledge. Epidemiol Mikrobiol Imunol 2014;63:221-5.

18. Fialova L, Petrackova M, Kuchar O. Comparison of different enzymelinked immunosorbent assay methods for avidity determination of antiphospholipid antibodies. J Clin Lab Anal 2017;31:e22121.

19. Fialova L, Malbohan I, Malickova K. Avidity of anticardiolipin antibodies-A factor that could be important for their detection by ELISA methods. J Appl Biomed 2014;12:277-84.

20. Almanzar G, Ottensmeier B, Liese J, Prelog M. Assessment of IgG avidity against pertussis toxin and filamentous hemagglutinin via an adapted enzyme-linked immunosorbent assay (ELISA) using ammonium thiocyanate. J Immunol Methods 2013;387:36-42.

21. Prince HE, Lape-Nixon M. Role of cytomegalovirus (CMV) IgG avidity testing in diagnosing primary CMV infection during pregnancy. Clin Vaccine Immunol 2014;21:1377-84

22. Ozarda Y. Reference intervals: current status, recent developments and future considerations. Biochem Med (Zagreb) 2016;26:5-16.

23. Dimitrov JD, Lacroix-Desmazes S, Kaveri SV. Important parameters for evaluation of antibody avidity by immunosorbent assay. Anal Biochem 2011:418:149-51.

24. Fialová L, Kuchař O, Petráčkova $M$, Malbohan I, Zima T. Avidity of anti-phospholipid antibodies in relation to their levels. Cent Eur J Immunol 2020;45:136-43.

25. Sanmarco M, Gayet $S$, Alessi MC, Audrain M, de Maistre $E$, Gris JC, de Groot PG, Hachulla E, Harle JR, Sie P, Boffa MC. Antiphosphatidylethanolamine antibodies are associated with an increased odds ratio for thrombosis. A multicenter study with the participation of the European Forum on antiphospholipid antibodies. Thromb Haemost 2007;97:949-54.

26. Sanmarco M, Alessi MC, Harle JR, Sapin C, Aillaud MF, Gentile S, Juhan-Vague I, Weiller PJ. Antibodies to phosphatidylethanolamine as the only antiphospholipid antibodies found in patients with unexplained thromboses. Thromb Haemost 2001;85:800-5.

27. Bertolaccini ML, Murru V, Sciascia S, Sanna G, Khamashta MA. The clinical value of testing for antibodies to phosphatidylethanolamine (aPE) in patients with systemic lupus erythematosus (SLE). Thromb Res 2012;130:914-8.

28. Zhang S, Wu Z, Zhang W, Zhang F, Li Y, Liu Y. Clinical performance of non-criteria antibodies to phospholipids in Chinese patients with antiphospholipid syndrome. Clin Chim Acta 2019;495:205-9.

29. Sanmarco M. ELISA for antiphosphatidylethanolamine antibody detection: high impact of assay buffer on results. J Immunol Methods 2010;358:9-16.

30. Ke K, Strango Zl, Harper PE, Zhao M. Influence of Phosphatidylethanolamine Concentration and Composition on the Detection of Antiphosphatidylethanolamine Antibodies by ELISA. J Clin Lab Anal 2016;30:689-96.

31. Vlachoyiannopoulos PG, Petrovas C, Tektonidou M, Krilis $S$, Moutsopoulos HM. Antibodies to beta 2-glycoprotein-l: urea resistance, binding specificity, and association with thrombosis. J Clin Immunol 1998;18:380-91.

32. Cucnik S, Kveder T, Artenjak A, Ulcova Gallova Z, Swadzba J, Musial J, Iwaniec T, Stojanovich L, Alessandri C, Valesini G, Avcin T, Cohen Tervaert JW, Rozman B, Bozic B. Avidity of anti-beta2-glycoprotein I antibodies in patients with antiphospholipid syndrome. Lupus 2012;21:764-5.

33. Totland C, Aarseth J, Vedeler C. Hu and Yo antibodies have heterogeneous avidity. J Neuroimmunol 2007;185:162-7.

34. Zeng Y, Lin Y, Wang $X$, Zhang Y, Peng F, Wang J, Jiang L, Liang S, Xiao Y. Assessment of a high-avidity IgG ANAs for the diagnosis and activity prediction of systemic lupus erythematosus. Clin Rheumatol 2020;39:2619-29.

35. Jianping L, Zhibing Y, Wei Q, Zhikai C, Jie X, Jinbiao L. Low avidity and level of serum anti-Abeta antibodies in Alzheimer disease. Alzheimer Dis Assoc Disord 2006;20:127-32. 